\title{
AS PRIMEIRAS LETRAS E A INSTRUÇÃO SECUNDÁRIA NA PROVÍNCIA DA PARAHYBA DO NORTE: ORDENAMENTOS E A CONSTRUÇÃO DA NAÇÃO. 1836-1884
}

\author{
Antonio Carlos Ferreira Pinheiro \\ Universidade Federal da Paraíba \\ acfp@terra.com.br ${ }^{1}$ \\ Cláudia Engler Cury \\ Universidade Federal da Paraíba \\ claudiacury@terra.com.br ${ }^{2}$ \\ Mauricéia Ananias \\ Universidade Federal da Paraíba \\ mauriceia.ananias@ hotmail.com ${ }^{3}$
}

\section{RESUMO:}

Este texto é fruto de um trabalho que vem sendo desenvolvido coletivamente por pesquisadores que têm se dedicado, mais particularmente, à história da educação paraibana no século XIX. Para tanto, o grupo de pesquisa tem trabalhado com a documentação encontrada no Arquivo Público da Paraíba, vinculado à Fundação Espaço Cultural FUNESC, no Instituto Histórico e Geográfico Paraibano - IHGP, a legislação que foi publicada na Coleção Documentos da Educação Brasileira, em 2004, bem como as mensagens dos presidentes de província encaminhadas à Assembléia Legislativa da Parahyba do Norte. Além dessa documentação, o referido grupo tem também se debruçado sobre os jornais e sobre os textos de memorialistas. Este trabalho tem como objetivo discutir o papel que tiveram as ações ordenadoras engendradas na Província da Parahyba do Norte, no período de 1836 a 1884, relacionadas às cadeiras de primeiras letras e à instrução secundária, esta última, marcadamente, institucionalizada a partir da criação do Lyceu Parahybano (1836). Partimos do pressuposto que tais ações ordenadoras e disciplinadoras estiveram consorciadas às expectativas da intelectualidade (administradores públicos, professores, jornalistas, bacharéis, entre outros) que tinha como propósito pensar e tentar efetivar politicamente as normatizações escolares, bem como pretendia que as práticas educativas pudessem contribuir com o processo de formação e consolidação do Estado-nacional brasileiro a partir das experiências que deveriam acontecer em escala provincial.

Palavras-chave: Instrução primária. Práticas ordenadoras na Paraíba. Instrução secundária.

\section{THE FIRST LETTERS AND THE SECONDARY EDUCATION IN THE NORTH PARAHYBA PROVINCE: ORDAINMENTS AND THE CONSTRUCTION OF NATION. 1836-1884}

\begin{abstract}
:
This text is fruit of a work that has been developed collectively by researchers who have been dedicating, more particularly, to the history of the of Paraíba education in the XIX century. For that the research group has worked with the documentation found in the Paraíba Public File, linked to the Foundation Espaço Cultural - FUNESC, in the Paraíba


Geographical and Historical Institute - IHGP, the legislation that was published in the Documents Collection of the Brazilian Education, in 2004, as well as the messages of the province presidents directed to the Legislative Assembly. Beyond that documentation, the referred group has also gone on the newspapers and the texts of memoirists. This work has the objective to discuss the part of the ordaining actions engendered in the North Parahyba Province, from 1836 to 1884 , related to the seats of first letters and to secondary education, this last one, remarkably, institutionalized since the creation of the Lyceu Parahybano (1836). We assume that such ordaining and disciplinarian actions were related to the expectations of the intellectuals (public administrators, professors, journalists, bachelors, and others) who had the purpose to think and try to politically put the school standards into effect, as well as they had the intention that the educational practices could contribute to the process of formation and consolidation of the Brazilian National-State from the experiences that should happen in provincial scale.

Keywords: Primary education. Ordaining practices on Paraiba. Secondary education.

\section{Introdução}

Este texto é fruto de um trabalho que vem sendo desenvolvido coletivamente no âmbito do Grupo de Pesquisa História da Educação no Nordeste Oitocentista - GHENO, criado em $2004^{4}$. Ao longo desses anos, o referido grupo tem empreendido um exaustivo trabalho de levantamento e catalogação de fontes primárias e secundárias acerca da história educacional brasileira e, mais particularmente, paraibana. Tal atividade foi inspirada a partir de uma das primeiras preocupações estabelecidas nos primórdios da organização do Grupo de Estudo e Pesquisa História, Sociedade e Educação - HISTEDBR, GT - Paraíba ${ }^{5}$, com o qual mantemos estreitos vínculos acadêmicos, visando ampliar e consolidar o campo da história da educação tanto na seara educacional quanto na da história.

O grupo de pesquisa tem trabalhado com a documentação encontrada no Arquivo Público da Paraíba, vinculado à Fundação Espaço Cultural - FUNESC, no Instituto Histórico e Geográfico Paraibano - IHGP, bem como aquelas que foram publicadas na Coleção Documentos da Educação Brasileira, em 2004 e as mensagens dos presidentes de província encaminhadas à Assembléia Legislativa da Parahyba do Norte. Além dessa documentação, o referido grupo tem também se debruçado sobre os jornais e sobre os textos de memorialistas.

Os desafios enfrentados pelos pesquisadores que trabalham com essa diversidade documental têm possibilitado a busca pela apreensão do cotidiano escolar e das práticas escolares como parte dos mecanismos destinados a um possível processo civilizador bem como da constituição e fortalecimento do Estado-nacional brasileiro. Todavia, essa tarefa não tem sido terreno fácil no caminho do sucesso da empreitada. A saída possível em termos de orientação de caráter teórico e metodológico tem se dirigido para a leitura da documentação oficial e, portanto prescritiva, "a contrapelo" como diria Walter Benjamim. Assim sendo, esses enfrentamentos de perspectivas têm possibilitado alimentar uma profícua discussão no interior do grupo, redundando em contrapartida na publicação desses estudos nos mais variados meios e formas de divulgação do conhecimento.

Portanto, em linhas gerais temos percebido que a tentativa de constituição da instrução pública paraibana foi precedida de uma intensa atividade legal, isto é, jurídicoadministrativa, demarcada por um significativo número de leis, regulamentos $\mathrm{e}$ normatizações, publicadas durante todo o período monárquico. A observância desse 
movimento de institucionalização nos possibilita segundo Faria Filho (1998), entender as estratégias adotadas pelo poder estatal objetivando dar ordenamento jurídico e disciplinar a partir do controle e da formalização de práticas antigas ou novas que fizeram parte de experiências vivenciadas por diversos agentes sociais. Salienta também o mesmo autor, que para além do ordenamento jurídico a legislação nos oferece entender outras dimensões, tais como as relativas à linguagem e à prática social, isto é, como práticas ordenadoras das relações sociais e como expressões e construções das relações e lutas sociais.

As práticas ordenadoras foram manifestas criando, removendo, fechando e reabrindo escolas de primeiras letras; determinando as matérias e os métodos de ensino; a forma de inspeção das aulas; a instituição do ensino misto; a caixa escolar, os materiais didáticos e os recursos financeiros necessários, bem como a proibição dos escravos freqüentarem as escolas. Com relação à carreira docente, normaliza a conduta moral, as jubilações, as licenças, os processos, os salários, as formas de suspensão, demissão e remoção, as aposentadorias, os concursos, os exames e a habilitação necessária para a admissão dos professores; os horários e as divisões em razão da localização das aulas e idade dos alunos. Quanto a estes, estavam representados numa parte significativa da legislação ao terem regulamentados os exames, castigos, férias, feriados, registros e matrículas (CURY, PINHEIRO, 2004).

Apesar de toda essa gama de questões e aspectos ter sido identificada na documentação, aqui nos deteremos em tecer considerações acerca do ordenamento das cadeiras de primeiras letras e às relacionadas com a instrução secundária, marcadamente, institucionalizada a partir da criação do Lyceu Parahybano.

\section{O ordenamento da instrução pública e as cadeiras de primeiras letras}

Na Parahyba do Norte, a Assembléia Legislativa foi instalada em 7 de abril de 1835. Espaço por excelência dos debates e promulgações da legislação provincial, esta seria, também, palco da recente e embrionária ordenação legal para a instrução pública, intencionando não só a criação das aulas de primeiras letras e a ordenação da profissão docente, mas concebendo, em especial, o controle sobre a tessitura que foi empreendida pelos seus inúmeros agentes sociais, principalmente, vinculados ao poder instituído, objetivando a constituição da ordem e da nacionalidade. Esse período corresponde a um momento da história em que o Estado monárquico e/ou a nação brasileira esteve em franco processo de consolidação, uma vez que "foi alçado por meio da construção progressiva de um complexo emaranhado de instituições políticas e administrativas." (GOUVÊA, 2008, p.21).

Seguindo essa mesma linha de raciocínio Mello (1996, p. 35) nos chama a atenção que a publicação da Lei de 15 de outubro de 1827 e, mais especificamente, alguns anos depois, no caso da Província da Parahyba do Norte, a criação do Lyceu Paraibano, em 1836, fizeram parte desse movimento empreendido pelas elites objetivando a construção da "nacionalidade" brasileira. Esse entendimento passava pela crença de que a base legal seria, em potência, a fundadora da escola moderna que levaria o império ao almejado desenvolvimento dos países considerados civilizados.

Em 1841, o Presidente da Província defendia a instrução pública como elemento de construção da moralidade - sendo esta a base da sociedade: 
Ha outros dois objectos que, que não me he licito passar em silencio pela sua gravidade fundamental no enteresse de todos. São elles a Instrucção Publica, e a Agricultura. [...] Ninguem ignora, que a moralidade he huma base principal da Sociedade no systema representativo, onde os homens são levados ao cumprimento dos seus deveres, antes pela convicção da utilidade, do que pelo temor das penas. Mas he hum perfeito desvaneio esperar, que se chegue a este gráu de moralidade sem proporcionar ao povo os meios de alcança-lo. $\mathrm{O}$ primeiro, e indispensavel meio he a Instrucção publica, que a nossa Constituição tem garantido, e em que todos de commum accordo nos esmeramos (PARAHYBA DO NORTE, 1841, p. 17).

Aliada à moralidade, estava presente nos debates o ideal de modernidade que justificou, por exemplo, a criação a cadeira de Desenho no Lyceo, em 1849, quando o presidente da província apontou-a como "conveniente à prosperidade da província" (PARAHYBA DO NORTE, 1849, p.14).

Ainda no mesmo ano, em outro relatório anunciou a publicação de dois regulamentos para garantir a uniformidade da instrução pública. Nesse sentido, o presidente da Província projetou a criação da Diretoria da Instrução Pública e a fiscalização das aulas que deveria ser realizada pelos Comissários como garantia do seu adequado funcionamento, resultante do exercício magisterial dos professores (PARAHYBA DO NORTE, 1849).

Os ideais do progresso e da civilização eram conclamados para o convencimento da população enviar seus filhos à escola, uma vez que ela era percebida por esses governantes como rústica e ignorante. Segundo eles, "ordinariamente indolentes e pobres utilizam-se muito cedo do trabalho dos filhos ainda tenros para o serviço do campo, ou para qualquer outro mister immediatamente lucrativo e deixão de mandá-lo as escolas" (PARAHYBA DO NORTE, Província,1850, p.10). A falta de apreço do povo para com a instrução, aos olhos dos legisladores, justificava tal postura social e cultural.

A ação da instância provincial para a institucionalização da instrução pública primária na Parahyba do Norte, como podemos perceber tanto a partir da análise da legislação quanto dos discursos do poder público provincial, mostram as famílias dos possíveis alunos como ignorantes e adversas à instrução. Os professores aparecem representados como despreparados para a tão nobre missão de instruir e educar a juventude. Assim, aos mestres e à família era atribuída a responsabilidade pelo péssimo estado da instrução pública. Nesse sentido, ao Governo provincial caberia organizar a instrução elaborando as leis e os regulamentos. Contudo, seria de competência dos pais e/ou tutores das crianças e aos professores efetivarem o que estava nos prognósticos daquelas normatizações.

O regulamento de 15 de janeiro de 1849 prescreveu a criação do cargo de Diretor Geral da Instrução Pública que deveria ser nomeado pelo presidente da província e teria como responsabilidades inspecionar os estabelecimentos de instrução, as aulas públicas, os professores; regular o ensino público nacional através do acompanhamento e proposição dos seus ramos, matérias, métodos, compêndios e regulamentos. Além disso, caberia a ele informar, ao governo, sobre a conduta dos empregados da instrução, bem como indicar as medidas coercitivas quando necessárias. Todas essas funções deveriam, anualmente, ser registradas e encaminhadas ao presidente da província, com indicações e propostas de melhoramento dos problemas encontrados. 
A tarefa de inspeção seria partilhada com os Comissários existentes em cada município. Segundo a legislação, deveria "[haver] em cada município um, ou mais Comissários da Instrução Publica, nomeados pelo Diretor Geral com aprovação do Presidente da Província” (CURY, PINHEIRO, 2004, p.21).

Cada um desses homens faria a fiscalização da sua localidade e encaminharia não só as informações sobre o estado de funcionamento da instrução, como também acerca da residência e frequiência dos professores. A esses últimos era livre o exercício do ensino público, desde que se mostrassem habilitados com carta que atestasse o exame na matéria postulante, idoneidade moral e boa saúde. Todas as aulas públicas e particulares estavam sujeitas a essa inspeção.

Em relatório emitido em 1853 ao Presidente da Província, o Diretor da Instrução Pública, Manrique Victor de Lima, dizia não existir, antes dos Regulamentos de 1849, uma organização da instrução, ou seja, apontou-o como uma necessidade que garantisse à racionalização dos espaços destinados a instrução, entre outros aspectos. Indicava, a cada novo relatório que as Aulas deveriam acontecer em outro espaço, que não a casa dos professores, considerando-os espaços "promíscuos" e impróprios para o aprendizado. Em um dos seus discursos enfatizava a necessidade de maior controle sobre os professores, orientado os Comissários a exigirem os seus atestados de residência. Tais mecanismos de controle demonstram, nitidamente, o processo de centralização que o poder provincial desejava exercer, uma vez que esse tipo de fiscalização estava prevista nas ordenações ainda oriundas do regimento das câmaras municipais, decretado em $1^{\circ}$ de outubro de 1828 , que destinava às câmaras municipais a fiscalização das Aulas (BRASIL. Lei de $1^{\circ}$ de outubro de 1828, 1981). Nessa reconfiguração, a fiscalização deveria ser feita tendo como base a ação dos professores que abrangia desde a responsabilidade de garantir lugar apropriado à realização das aulas, fazer as matrículas e acompanhar o desenvolvimento dos alunos até a administração do cotidiano pedagógico. Ao final de cada trimestre o mesmo deveria enviar um relatório às autoridades locais e deveria se apresentar para provar sua residência e assiduidade, o que garantiria o pagamento do seu ordenado.

Esse primeiro regulamento de 1849 anunciara a incipiente tentativa do governo provincial em atender o que fora prescrito pelo Ato Adicional de 1834, qual seja, assumir a regulação e a físcalização das cadeiras de primeiras letras. A criação de uma Diretoria Geral da Instrução Pública viria atender esse propósito. O conflito entre a estrutura legal anterior e as responsabilidades que deveria assumir na inspeção das escolas passava pela efetivação do controle sobre os professores. $\mathrm{O}$ estado provincial agiria nesse ramo da vida pública e para tal, a legislação deveria, em primeiro plano, garantir que o mesmo pudesse controlar tal atividade através da estrutura administrativa que tinha como centro a presidência da província e homens de sua responsabilidade como representantes desse poder nas localidades.

Essa iniciativa - como cumprimento legal - pode ser entendida a partir da própria organização administrativa e política da província. Considerada co-participe na constituição do Estado Nacional, com ela ficaria a responsabilidade da organização nas regiões. Para Mattos (2004, p. 225), "os empregados públicos [são] entendidos como agentes da administração pública, e também da centralização" numa perspectiva "de que o conjunto dos agentes deve ser entendido como um conjunto de dirigentes, em que pesem as diferenças internas e o grau relativo de homogeneização".

Considerando essas diferenças, o "olhar vigilante" (MATTOS, 2004, p. 216) do poder imperial e do governo provincial era abalizado pela ação de fiscalização centralizada na presidência da província com a intenção de alteração da ordenação anterior, associada ao atraso português, e a perspectiva de implementação gradativa de um novo modelo de 
instrução pública. A presença, instituidora, do poder público nas localidades caracterizaria esse período de transição.

A análise do Regulamento de 20 de janeiro de 1849, decretado no mesmo ano, e dos demais documentos, explicitará de uma forma mais minuciosa essa intenção. Anunciando, a partir de pressupostos higienistas, a responsabilidade em procurar uma sala sadia e "em tudo apropriada ao estabelecimento de uma escola", essa ordenação fora apresentada apregoando a verificação dessa tarefa pelos inspetores. Nessa nova orientação, a convivência numa mesma casa da família dos (as) professores (as) e das Aulas de primeiras letras não era aceita como saudável para o desenvolvimento da instrução, conforme já salientamos anteriormente (CURY, PINHEIRO, 2004, p.22).

Para a criação desse novo espaço de escolarização, os artigos seguintes estabeleciam as regras que deveriam reger o espaço interno dessas escolas: "em frente aos meninos [...] haverá uma Imagem de Cristo e o retrato de S.M. Imperial", "o estrado", onde ficará a mesa do professor, deverá ficar, simultaneamente, na entrada da sala e em frente aos meninos. Essa posição serviria para que o mesmo visualizasse e acompanhasse toda a rotina da sala. A utilização das paredes também recebeu prescrições: regulamentos e penas máximas da religião e da moral ocupariam o mesmo espaço que as pedras pretas, onde se desenharia "o abecedário e um mapa do Império do Brasil" (CURY, PINHEIRO, 2004, p. 22).

A limpeza da escola e o registro obrigatório que o professor deveria realizar de seus alunos apareceriam como constitutivas dessa arrumação. Ainda como parte desse arranjo espacial, a placa a ser colocada na porta da sala apresentaria o método prescrito para a instrução pública primária da província da Paraíba: o simultâneo.

Esse método, segundo Lesage (1999), tem origem cristã e é atribuído a JeanBaptiste de la Salle que o criou no século XVII, com a intenção de um só professor atender a várias crianças ao mesmo tempo. Nas suas origens, segundo o mesmo autor, o método trabalhava com coletivos de alunos divididos em grupos em função da matéria que seria estudada. $\mathrm{O}$ ensino dado pelo professor era dirigido não a um único aluno como no método individual, mas a 50 ou 60 alunos ao mesmo tempo. Todavia, segundo Cury (2006, p. 50), "analisando os textos dos regulamentos de 1849, sobre os métodos de ensino, pode-se dizer que se tratava, na província da Parahyba, da utilização de um método misto".

A combinação do método individual com o método mútuo e o prenúncio da utilização do método simultâneo foram caracterizados como método misto, demonstrando esse período como transitório entre a predominância de uma escolarização baseada na escola doméstica, isto é, aquela que funcionava no espaço doméstico do professor e a escola considerada moderna, em outras palavras, a escola que deveria funcionar em espaço destinado exclusivamente para a instrução. O que reforça a idéia da necessidade de constituição da escola pública. Essa última, baseada na ação sistematizada e conjunta do professor em relação ao coletivo dos alunos, fundamento do método simultâneo, a partir de 1849, previsto oficialmente para a província da Parahyba do Norte.

Apesar da diversidade de realidades nas diversas províncias, podemos afirmar que, 
Dessa maneira, em um processo lento, mas contínuo, de transformações, a difusão do método de ensino simultâneo gerava questionamentos sobre a necessidade de criar uma organização mais racional do ensino escolar, e temas como o estabelecimento de critérios que permitissem dividir os alunos em grupos, modos de otimizar o tempo de aprendizado, que conteúdos abranger e como organizá-los passam a ser objetos de discussão nos meios pedagógicos e de legislação pertinente (FERNANDES, 2006, p.68).

Essa nova conformação, por ser incipiente, conviveria com as aulas anteriores caracterizadas pela fragmentação; ora com a centralização das ações na figura do professor, ora, ainda que esse mantivesse o comando, na divisão das tarefas cotidianas da escola com os monitores.

Dessa forma, nas aulas prescritas e anunciadas por esse regulamento, ao professor era permitido receber ajuda no seu dia-a-dia. Para isso, poderia escolher os seus alunos "mais assíduos, inteligentes e de melhor conduta". Esses, nomeados "decuriões" teriam como funções a inspeção das mesas, carteiras e a vigilância em relação àqueles que não se portassem bem; deveriam chegar meia hora antes dos outros; acompanhar a ausência; verificar, quando solicitado, a limpeza e higiene dos demais alunos. Além desses monitores de carteiras haveria o monitor geral que só atuaria em casos considerados de extrema necessidade: ausência do professor. No entanto, não havia, no regulamento, nenhuma orientação pedagógica ou instrucional para esses casos e nem para o dia-a-dia das aulas (CURY, PINHEIRO, 2004, p. 22).

De acordo com Lesage (1999, p. 11-12), ao se pensar a escola a partir das orientações do método mútuo, oficialmente adotado no Brasil a partir da Lei Geral de 15 de outubro de 1827, percebe-se que a monitoria era uma das bases de sustentação dessa orientação pedagógica.

As aulas existentes na Parahyba do Norte em 1842, segundo Pinheiro (2002, p. 27), eram 22 cadeiras distribuídas nas diversas localidades. Em 1853, o mapa apresentado pelo Diretor da Instrução Pública indicava 36 cadeiras, com 1239 alunos freqüentes (PARAHYBA DO NORTE, 1853). Para o ano de 1858, o relatório do presidente da província dizia existir 66 cadeiras de instrução primária atendendo a 1941 alunos (PARAHYBA DO NORTE, 1858).

Esses números indicavam um crescente aumento no número de Aulas e de alunos freqüentes. Ao mesmo tempo, os discursos reclamavam da falta de professores habilitados para a condução das mesmas. Isso poderia ajudar a explicar $o$ fato de que monitores/decuriões fossem chamados a auxiliar os professores.

A exigência do bom comportamento dos alunos passava pela necessidade do cortejamento ao professor, retirada do chapéu, reverência às autoridades e, também, pelo atendimento às proibições prescritas: venda ou troca de qualquer objeto no interior da escola; portar livros diferentes dos recomendados; falar, sair do lugar sem licença prévia; faltar à aula. O controle do comportamento extrapolava as paredes escolares, pois os alunos deveriam ser acompanhados por um condutor até a sua chegada em casa. As orações e rezas, no início e término das aulas em voz alta, faziam parte da rotina escolar. A obediência a Deus e ao poder terreno se confundia: uma vez por mês, após as orações era obrigatória a leitura dos regulamentos da escola. 
$\mathrm{O}$ atendimento ao bom comportamento era reconhecido através das recompensas, que estimulavam a competição entre os alunos. Prêmios, bilhetes de satisfação, fitas, listas de honra visavam publicizar a ação merecedora de aprovação por parte dos alunos e servir de exemplo aos demais.

Para Lesage (1999, p.21), Bell e Lancaster, e seus seguidores franceses, defendiam a emulação como uma estratégia fundamental de motivação aos estudos. A distribuição de prêmios e lugares de destaques e honras marca uma parte significativa da legislação, bem como a possibilidade de punição, também, a partir da exposição pública.

Na mesma orientação àquelas atitudes não merecedoras de exaltação e emulação, os castigos eram permitidos. Na legislação, estes eram concebidos como "capaz[es] de manifestar às crianças a falta que cometerão, de lhes causar vergonha e arrependimento, e de servir de expiação ao passado, e de preservativo ao futuro" eram aplicados de acordo com os erros e caráter de cada criança/aluno e a partir da recomendação da frieza e racionalidade do professor. A esse último era recomendado, segundo a lei, que não se deixasse "possuir de cólera" no ato da aplicação das punições que eram: distribuição de notas más, perda do lugar alcançado nos exercícios, retirada ou privação dos prêmios, rótulos pendurados no pescoço "com as palavras: falta de verdade, indisciplina, falador, preguiçoso, etc.”, ficar de joelhos em sala ou em horário da recreação, impedimento provisório de assistir às aulas e por fim, a expulsão definitiva do aluno das aulas; nesse último caso somente com a autorização do presidente da província, antecedendo a comunicação às "autoridades respectivas" (CURY, PINHEIRO, 2004,p. 25).

Ainda segundo o regulamento, a educação religiosa aparecia como uma fundamentação dessas aulas; sua defesa era feita não só como uma disciplina a ser ensinada, mas como uma parte significativa do ensino realizado ao início e ao final das aulas em todos os dias letivos. À certeza de seu cumprimento, os professores deveriam desenvolver nos pais dessas crianças "o zelo, que devem ter na instrução religiosa" de seus filhos. Todo e qualquer espaço e oportunidade deveriam ser utilizados para ensinar o dever para com "Deus, ao Soberano" bem como "a sua família e país". Novamente a associação entre o poder divino e poder terreno através da exaltação ao monarca, à nação e à família (CURY, PINHEIRO, 2004, p.26).

Além do ensino religioso, de acordo com o regulamento, compunham as aulas de primeiras letras, ou seja, às escolas de aprender a ler, escrever e contar os seguintes ensinamentos: leitura, caligrafia, a aritmética até proporções, a gramática portuguesa, noções gerais de geometria prática sem demonstrações.

As escolas passaram, a partir do regulamento de 1849, a serem organizadas em "três divisões principais" não só considerando os "objetos de ensino", mas, também, a "idade" dos alunos (CURY, PINHEIRO, 2004, p.26).

Essa ordenação prenuncia alguns princípios da escola moderna, calcada na seriação e graduação dos ensinamentos oferecidos. Esses preceitos podem ser verificados na propositura de avaliação para aproveitamento dos estudos e pela orientação de aprofundamento desses objetos ou matérias na passagem de uma divisão de ensino para outra, conforme previa o referido regulamento.

Ainda na proposta da Leitura, a indicação de que os professores deveriam conhecer os "melhores métodos de leitura" negando o "antigo soletramento" até então utilizado na província. A referência indica, considerando as diferenças entre as províncias, ser o método de soletração usado em várias delas durante todo o período imperial. As críticas a esse método condizem com o que se propunha, também, nas outras províncias que o consideravam atrasado para a realidade daquele momento (SÁ, XAVIER, 2006, p. 6). 
No discurso dos legisladores, os novos métodos deveriam passar pela defesa da pronúncia e entonação correta das palavras e das frases. Os exercícios seriam realizados a partir da organização dos alunos em semicírculos que fariam a leitura de acordo com a ordem de aproveitamento adquirido na última sessão. As correções seriam feitas pelos próprios alunos e só, em último caso, quando os alunos não soubessem realizá-las é que seriam feitas pelos professores. Também nessas aulas os "melhores" alunos poderiam vir a ser premiados com alguns "signos de distinção" que seriam colocados nos peitos dos mesmos. Essa prática concorreria para a efetivação de uma das prescrições relativa à proposta de emulação já anunciada anteriormente. Nesse sentido, não somente as críticas eram direcionadas às famílias e aos professores, mas a metodologia de ensino adotada por esses últimos na sala de aula também era vista como um elemento de racionalização e modernização da instrução pública.

Para atender a tal propósito, havia a defesa de que o aprendizado da leitura e da escrita deveria se basear no ensino das coisas úteis que poderiam servir, na prática, à vida desses alunos. Assim, de acordo com o regulamento de 20 de janeiro de 1849:

[...] Para a leitura de manuscritos se lhe dará a ler de preferência manuscritos, ou cadernos litografados, contendo coisas da vida que lhes seja útil conhecer, como recibos, arrendamentos, contratos, vendas, memórias sobre obras, ou aliás encerrando noções elementares de agricultura, ou sobre as artes, ofícios, etc. (CURY, PINHEIRO, 2004, p.27).

A defesa de que o aprendizado das crianças deveria passar pelo conhecimento da realidade, ou da suposta realidade percebida pelos legisladores, incluía as atividades comerciais nascentes na vida urbana, sem se esquecer das atividades agrícolas característica, ainda, dessa mesma sociedade. ${ }^{6}$

\section{Lyceu Parahybano: modelo de instrução secundária na Parahyba do Norte}

Fundado em 24 de março de $1836^{7}$, um ano antes da criação do Colégio de Pedro II, no Município da Corte, no Rio de Janeiro, sob a denominação inicial de Lyceu Provincial ${ }^{8}$ constituiu-se como uma importante instituição de instrução secundária que permaneceu em funcionamento ao longo de todo o século XIX. Ainda hoje, se apresenta como uma instituição pública de referência na cidade de João Pessoa, e no próprio Estado. Com a sua institucionalização de fato inicia-se a organização de um modelo de instrução secundária que prevaleceu até o final do período imperial e que serviu de referência para outras instituições secundárias tais como o "Colégio de instrução secundária para meninos" (CUNHA, 2000), fundado pelo Padre Mestre Inácio de Sousa Rolim, em 1843, em Cajazeiras. O referido Colégio teve prestígio e importância como instituição secundária por localizar-se no sertão e atender às necessidades de instrução dos filhos das famílias mais abastadas da região. Segundo Pinto (1977, p. 265), o Colégio foi considerado "foco importante de instrucção, não só para os sertões desta província como para os do Ceará e Rio Grande do Norte". Barroso (1867, p. 63) também nos informa que no referido Colégio ensinava-se "latim, francez, geometria, phiosophia, rhetorica; e era freqüentado por 57 alumnos."

Em 1858 foi criado o Colégio Nossa Senhora das Neves dedicado à instrução das meninas oriundas de famílias ricas. Segundo Egito (2008, p.127) é 
Importante atentar que se tratava de uma escola pública, conforme rezava a Lei $n^{\circ} 13$, de 4 de novembro de 1858 , no seu Art. $3^{\circ}$ e que para ela poderia o governo despender até a quantia de 10:000\$ réis. Nesse sentido, tratava-se de um colégio subsidiado pelo governo, mas destinado à elite local. A idéia de acesso universal à instrução, mesmo que esta fosse pública, ainda não vigorava no Brasil. $\mathrm{Na}$ verdade, constitui-se como direito somente a partir da República.

O Colégio, apesar de ser mantido em grande parte com recurso público, também contava com as mensalidades pagas pelas alunas, cujo valor que variava, de acordo com tipo de vínculo.[...] No entanto, ainda estava previsto pelo regulamento do Colégio, no Artigo $6^{\circ}$ que na classe das internas, poderia haver a admissão gratuitamente de duas órfãs desvalidas, na classe das semi-pensionistas, três, e na das externas, seis.

Quanto ao Externato (Escola) Normal, somente, a partir de 1884, entrou em funcionamento, o com a finalidade de formar professores. Para Gomes (2008, p.99) a criação dessa instituição formativa se coadunava

[...] com o processo vivido de uma forma geral em todo o mundo, que é a passagem da educação realizada através da "impregnação cultural" para o progressivo controle do Estado (o "Estado docente"). Isso significa que se, antes, a instrução estava restrita às iniciativas de particulares, tais como de instituições religiosas, de caridade e das próprias famílias, agora ela passa a ser encarada como tarefa do poder público. Mais do que isso, ela passa a fazer parte da política oficial, parte importante do projeto de nação que se quer implantar naquele momento. Isso não significa que as iniciativas particulares tivessem desaparecido completamente do cenário da educação elementar no Brasil do século XIX. Elas continuaram a existir mesmo com a expansão da participação do Estado na instrução.

Retornando ao Lyceu Parahybano que funcionou, inicialmente, no primeiro andar do edifício da Assembléia Legislativa Provincial, trazia em seu quadro de disciplinas as cadeiras de Latim, Francês, Retórica e Filosofia. Vale salientar que na cadeira de Retórica eram também ensinados conteúdos de geografia, cronologia e história, além de poética. A definição dessas cadeiras seguiu os objetivos do curso de Humanidades que já existia na Parahyba do Norte desde $1831^{9}$ e que visava atender a juventude que vislumbrava se preparar para o ensino superior, isto é, principalmente, para a Faculdade de Direito de Olinda e posteriormente do Recife ${ }^{10}$ ou para a Faculdade de Medicina da Bahia. Assim, a estruturação do ensino secundário na Parahyba do Norte seguiu as mesmas diretrizes que caracterizaram os outros liceus e escolas secundárias criadas no Brasil.

O aparecimento de liceus provinciais a partir de 1835 , e a criação do Colégio Pedro II na Corte, em 1837, representam, no campo do ensino público, os primeiros esforços no sentido de imprimir alguma organicidade a esse ramo do ensino. [...] Destinava-se precìpuamente a preparar para o ingresso [de estudantes] nas Faculdades [...]. O ingresso nos cursos superiores era a meta visada por todos os jovens que buscavam os estudos secundários, e o estudo parcelado dos preparatórios exigidos para a matrícula nas Academias (HAIDAR, 1972, p.14-16). 
O Lyceu Parahybano, em 1838, dois anos depois de sua criação, contava com 120 alunos freqüentando as suas cadeiras, entretanto, da avaliação realizada pelo presidente da província, depreendemos que o referido estabelecimento, seja pela sua condição de novo ou pela falta de disposições legislativas, passava por "embaraços e tropeços" (PARAHYBA DO NORTE, 1838). Essa fragilidade no funcionamento do Lyceu gerou debates em torno da estruturação das cadeiras que faziam parte de sua proposta curricular. Esse aspecto foi resolvido com a publicação de uma segunda legislação no ano seguinte (1839). ${ }^{11}$ Nela verificamos a criação de duas novas cadeiras: uma de Inglês e outra de Geografia, Cronologia e História, o que significa que as matérias de geografia, história e cronologia ganhavam autonomia sendo tratadas em separado e não mais como conteúdos ministrados pela cadeira de Retórica. Identificamos ainda, algumas recomendações sobre o ensino dessas cadeiras, ressaltando quais os recursos didáticos que deveriam ser utilizados pelo professor de geografia e os procedimentos metodológicos para o ensino de inglês ${ }^{12}$.

No que concerne ao perfil do corpo docente, este era formado por intelectuais reconhecidos na província. Contudo, não eram muitos e a lei de 1839 facultou aos sacerdotes regulares a oportunidade de poderem ser providos nas cadeiras do Lyceu ${ }^{13}$. Há um dado interessante que ainda não foi devidamente explorado pelas pesquisas do Grupo (GHENO) e que nos chamou atenção na leitura do livro Rocha (2009, pp.81-86). Trata-se da história de um homem pardo de nome Manoel Pedro Cardoso Vieira que se formou em Direito no Recife entre os anos de 1863 e 1870 e que ao retornar à cidade da Parahyba tornou-se professor das cadeiras de Retórica e Geometria do Lyceu Parahybano atuando também, como era comum à época, como jornalista, criando um "irreverente semanário", intitulado o Bossuet da Jacoca (1875), com idéias de cunho liberal. A história e a presença de um homem pardo como Manoel Pedro Cardoso Vieira entre os Lentes, da única instituição secundária pública da província naquele momento, pode trazer novos elementos para pensarmos o "processo civilizador" que se pretendia engendrar aos alunos do Lyceu Parahybano já que o professor engajou-se nas campanhas abolicionistas.

A participação de religiosos, da Igreja Católica, no âmbito da instrução pública e privada era estimulada pelos próprios gestores da província, conforme verificamos na legislação consultada ${ }^{14}$. Entretanto, para além das normatizações havia uma cultura disseminada na sociedade brasileira que entendia que para formar "homens de bem" (e por que não também de bens!) era necessário uma boa formação moral, principalmente, daqueles que estivessem envolvidos com as atividades instrucionais. Observemos:

Nem vós duvidaes, nem há ahí alguém, que ignore, que a influencia da Religião sobre os costumes, e a moral tem huã força benéfica, e sólida sobre tudo em Estado novo, onde os sentimentos naturaes de respeito e adoração ao Ente Supremo suprem a falta de conhecimento dos deveres do homem para com Deus, para com outros homens e para consigo mesmo (PARAHYBA DO NORTE, 1837, p.12).

O debate que se estabelece até os dias atuais em torno dos objetivos do ensino de nível médio (ou secundário) ora entendido numa perspectiva propedêutica, ora numa perspectiva profissionalizante, ora de formas consorciadas, remonta a sua origem. $\mathrm{Na}$ discussão sobre o desmembramento de conteúdos da disciplina de retórica, conforme mencionada anteriormente, a problemática da necessidade do Lyceu Parahybano implantar uma "aula" que "profissionalizasse" os seus educandos para o comércio ou para gerir os negócios do estado, já estava posta desde os primeiros anos de sua existência. Essa questão pode ser depreendida na falla de Joaquim Teixeira Peixoto d'Albuquerque, em 1838: 
Seria igualmente interessante que a Assemblea se lembrasse de criar hua Aula de Comercio, em aqual se ensinasse a escripturação por partidas dobradas, redução de pesos, e medidas, Câmbios, Seguros, avarias \& a criação d'esta Cadeira acarretaria com sigo não poucos benefícios, por que devendo esta Província pela sua localidade, e excellente Porto, ser bastante comercial, lucraria não pouco, que se applicassem aos estudos mercantis, quando não a todos pelo menos aos mais necessários, aqueles que a essa vida se quisessem dedicar. O Verdadeiro Negociante e hum homem instruido; pelo menos no que é relativo ao se o emprego, e occupação: elle deve conhecer a Legislação a que está sujeito, pelo genero de vida que adoptou, as penas em que incorre, pela infracção de qualquer Contracto; o modo pratico por que deve proceder á escripturação dos seos Livros, e tudo depende de hum estudo bem coordenado. Esta Aula se acha em todos os Paizes civilisados, e entre nós já tem lugar em algumas Provincias do Império; a sua criação é certamente hum preceito da Lei Geral de 4 de outubro de 1831, Art. 96, que manda - que nenhum individuo possa sêr admettido aos lugares de Fasenda, sem que apresente exame de quasi todas essas matérias (PARAHYBA DO NORTE, 1838, p.9-10).

Entretanto, nos embates e nas correlações de forças que irão se estabelecer, pelo menos até as primeiras décadas da república, a perspectiva propedêutica e preparatória para os exames superiores será a vencedora. Isto nos indica que apesar do Lyceu Parahybano se constituir uma instituição pública, mantida com recursos do Estado, atendeu, prioritariamente, as demandas da elite local e masculina. Muitas questões sobre o Lyceu Parahybano ainda estão sendo exploradas pelos pesquisadores como os métodos punitivos e disciplinares, a distribuição do tempo escolar, as manifestações dos alunos do Lyceu nas ruas da cidade da Parahyba em protesto conta a saída de um dos diretores da instituição - como nos reportam os jornais do período - a organização das matérias ministradas no Lyceu como as aulas de História e geografia que deveriam apresentar conteúdos específicos de história e geografia da Parahyba.

\section{Considerações finais}

A análise da documentação produzida no período imperial na província da Parahyba do Norte demonstra que não apenas a legislação atuava no sentido de contribuir para a institucionalização da instrução pública paraibana. As falas oficiais acerca da atuação de famílias de alunos e de professores demonstram a preocupação com a disseminação da escola.

Em diversos discursos do poder público provincial, as famílias são mostradas como rústicas, indolentes e ignorantes, que se aproveitavam do trabalho das crianças para auxiliar o sustento da casa, preterindo a escola que já aparecia naquele momento - no discurso oficial - como central na formação da juventude. Além disso, enfrentavam dificuldades como ausência de vestimenta decente e de utensílios necessários para a atividade escolar, como livros, papéis e penas, o que impossibilitava uma frequiência adequada às aulas. Em suma, não dariam o devido apreço à aquisição do conhecimento escolar. 
Já os professores, eram representados como pessoas sem vocação para a tarefa a que se propunham, sem estímulos nobres, o que os impediam de compreender a missão trazida pela função pedagógica, vítimas de baixos salários e dispersos pelo território.

No contexto do mesmo discurso, era também salientado que a atuação do governo provincial se fazia necessária, para a fiscalização e controle do professorado, único meio de imprimir-lhes zelo e satisfatórias atividades: ação materializada na elaboração de uma legislação abastada em ordenamentos disciplinadores e de controle do cotidiano desses primeiros mestres públicos, conforme foi demonstrado. Em contrapartida a instrução secundária, ou melhor, os professores que ensinavam nesse nível de ensino, especialmente os lentes do Lyceu Parahybano, gozavam de grande prestígio social, cultural e político, uma vez que muitos deles eram os próprios administradores do poder provincial ou eram bacharéis em direito, jornalistas, literatos ou religiosos vinculados a igreja católica.

\section{Referências}

BARROSO, J. L. A instrucção publica no Brasil. Rio de Janeiro: B. L. Garnier, 1867.

BASTOS, M. H. C.; FARIA FILHO, L. M. (Org.). A escola elementar no século XlX. O método monitorial/mútuo. RS: Universidade de Passo Fundo/EDIUPF, 1999.

BRASIL. Lei de $1^{\circ}$ de outubro de 1828. Dá nova forma às Câmaras Municipaes, marca suas attribuições, e o processo para a sua eleição, e dos Juizes de paz. CAMPANHOLE, A.; CAMPANHOLE, H.L. Constituições do Brasil. São Paulo: Atlas, 1981.

CUNHA, J. R. da. Colégio Nossa Senhora de Lourdes: Cajazeiras. João Pessoa, PB: A União, 2000.

CURY, C. E. Métodos de ensino e formas de controle sobre o cotidiano escolar na instrução pública da Parahyba do Norte (1835-1864). SCOCUGLIA, A. C.; MACHADO, C. J. dos S. (Org.). Pesquisa e historiografia da educação brasileira. Campinas, Autores Associados, 2006.

CURY, C. E.; PINHEIRO, A. C. F. A Instrução Secundária na Província da Parahyba do Norte (1822-1889): o Lyceu Parahybano. In: Anais do VII Seminário Nacional de Estudos e Pesquisas - História, Sociedade e Educação no Brasil. Formato Digital. Campinas: UNICAMP, 2006.

(Orgs.). Leis e regulamentos da instrução da Parahyba do Norte no período imperial. Coleção Documentos da educação brasileira [recurso eletrônico] - Dados eletrônicos- Brasília: Instituto Nacional de Estudos e Pesquisas Educacionais Anísio Teixeira, 2004.

EGITO, P. H. T. do. A instrução feminina na capital da Província da Parahyba do Norte: O Colégio de Nossa Senhora das Neves (1858 - 1895). In: PINHEIRO, A. C. F.; FERRONATO, C. (Orgs.). Temas sobre a instrução no Brasil imperial (1822-1889). João Pessoa, PB: Universitária - UFPB, 2008.

FARIA FILHO, L. M. de. A legislação escolar como fonte para a História da Educação: uma tentativa de interpretação. In: (Org.). Educação, modernidade e civilização: 
fontes e perspectivas de análise para a história da educação oitocentista. Belo Horizonte, MG: Autêntica, 1998.

FERNANDES, G. Composição de textos na escola brasileira: em busca de uma história. Do Ratio Studiorum aos manuais de estilo do final do século XIX. São Paulo, SP: FE/USP, 2006. (Tese de doutoramento)

GOMES, J. de P. C. A profissionalização dos professores na Parahyba do Norte (18341889). In: PINHEIRO, A. C. F.; FERRONATO, C. (Orgs.). Temas sobre a instrução no Brasil imperial (1822-1889). João Pessoa, PB: Universitária - UFPB, 2008.

GOUVÊA, M. de F. S. O império das províncias: Rio de Janeiro, 1822-1889. Rio de Janeiro, RJ: Civilização Brasileira, 2008.

HAIDAR, M. de L. M. O ensino secundário no Império brasileiro. São Paulo: Grijalbo, Editora da Universidade de São Paulo, 1972.

LESAGE, P. A pedagogia nas escolas mútuas do século XIX. BASTOS, M. H. C.; FARIA FILHO, L. M. de. Escola elementar no século dezenove: o método monitorial/ mútuo. Passo Fundo, RS: Ediupf, 1999.

MATTOS, I. R. de M. O tempo saquarema. A formação do Estado Imperial. São Paulo: Editora Hucitec, 2004.

MELlo, J. B. de. Evolução do ensino na Paraíba. João Pessoa, PB: Secretaria da Educação e Cultura; Conselho Estadual de Educação, 1996.

PARAHYBA DO NORTE, Província. Discurso com que o prezidente da província da Paraíba do Norte, fez a abertura da sessão ordinária da Assembléa Provincial no mez de janeiro de 1837. Cidade da Paraíba, Typ. Paraibana, 1837.

Relatório apresentado á Assembléa Legislativa provincial pelo presidente da mesma província, o tenente coronel Frederico Carneiro de Campos, em 3 de maio de 1846. Pernambuco, Typ. Imparcial, por S. Caminha, 1841.

Exposição feita pelo tenente coronel de engenheiros Frederico Carneiro de Campos na de presidente de província ao exmo. vice-presidente della no acto de passar-lhe a administração da Presidencia em 16 março de 1848. Parahyba, Typographia de J.R. da Costa, Rua Direita n ${ }^{\circ} 8,1848$.

Relatorio apresentado a Assembléa Legislativa Provincial da Parahyba do Norte pelo excellentissimo presidente da provincia, o bacharel João Antonio de Vasconcellos, em o 1.o de agosto de 1849. Parahyba, Typ. de José Rodrigues da Costa, 1849.

. Exposição feita pelo dr. Antonio Coêlho de Sá e Albuquerque na qualidade de presidente da provincia da Parabyba [sic] do Norte no acto de passar a administração da provincia ao segundo vice-presidente, o excellentissimo senhor doutor Flavio Clementino da Silva Freire, em 29 de abril de 1853. Parahyba, Typ. de José Rodrigues da Costa, 1853. 
Relatorio apresentado á Assembléa Legislativa da provincia da Parahyba do Norte em 20 de setembro de 1858 pelo presidente, Henrique de Beaurepaire Rohan. Parahyba, Typ. de José Rodrigues da Costa, 1858.

SÁ, N. P., XAVIER, A. P. da S. Um olhar sobre a leitura e a escrita na cultura escolar de Mato Grosso (1837-1889). In: Anais do IV CBHE- Congresso Brasileiro de História da Educação: a educação e seus sujeitos na história. Goiânia: SBHE; UCG, 2006.

PINHEIRO, A. C. F. Da era das cadeiras isoladas à era dos grupos escolares na Paraíba. Campinas, SP: Autores Associados e Universidade de São Francisco. 2002.

PINTO, I. F. Datas e notas para a história da Paraíba (reprodução da edição de 1916), V.II, João Pessoa, PB: Ed. Universitária/UFPB, 1977.

ROCHA, S. P. da. Gente negra na Paraíba Oitocentista: população, família e parentesco espiritual. São Paulo, SP: UNESP, 2009.

${ }^{1}$ Coordenador do HISTEDBR- PB e pesquisador do GHENO.

${ }^{2}$ Coordenadora do GHENO e pesquisadora do HISTEDBR- PB.

${ }^{3}$ Pesquisadora do GHENO e do HISTEDBR-PB.

${ }^{4}$ O Grupo encontra-se vinculado, com a mesma denominação, ao Diretório do CNPq e a Linha de Pesquisa Ensino de História e Saberes Históricos do Programa de Pós-graduação em História da UFPB.

${ }^{5}$ Esse grupo de trabalho, no Diretório do CNPq está registrado como História da Educação na Paraíba e encontra-se vinculado a Linha História da Educação do Programa de Pós-graduação em Educação da UFPB.

${ }^{6}$ Sobre esse último aspecto ver discussão realizada por Pinheiro (2002, p. 87-88).

${ }^{7}$ Ver Lei no 11 de 24 de março de 1836. (CURY, PINHEIRO, 2004).

${ }^{8}$ Parte das discussões que faremos daqui em diante, com modificações, foi apresentada e publicada por Pinheiro e Cury (2006), nos Anais do VII Seminário Nacional de Estudos e Pesquisas História, Sociedade e Educação, sob o título: "A instrução secundária na Província da Parahyba do Norte (1822- 1889): o Lyceu Parahybano".

${ }^{9}$ Decreto de 14 de junho de 1831 do Conselho Adjunto.

${ }^{10}$ Segundo Barroso (1867, p.81) a partir da publicação do "Art. 286 dos Estatutos, publicados com o Decreto n. 1,134 de 30 de março de 1853, determinou a sua transferência para a cidade do Recife, que se effectuou em 1854."

${ }^{11}$ Lei JJ de 23 de março de 1839. (CURY, PINHEIRO, 2004).

${ }^{12}$ Ver Art. $2^{\circ}$ da citada lei.

${ }^{13}$ Ver Art. $5^{\circ}$ da citada lei.

${ }^{14}$ A regulamentação de conteúdos dogmáticos da Igreja Católica Apostólica Romana no âmbito das questões instrucionais será efetivada de forma ainda mais evidente no Art. $6^{\circ}$ da lei $\mathrm{n}^{\circ} 20$ de 6 de maio de 1837. (CURY, PINHEIRO, 2004).

Artigo recebido em: $\quad 07 / 06 / 2010$

Aprovado para publicação em: 12/07/2010 